\title{
Behavior of foundation soil improved by stone column under cyclic load
}

\author{
Kwa Sally Fahmi ${ }^{1, *}$, Mohammed Fattah $^{2}$ and Alena Shestakova ${ }^{3}$ \\ ${ }^{1}$ Peter the Great St. Petersburg Polytechnic University, Polytechnicheskaya, 29, St. Petersburg, \\ 195251, Russia \\ ${ }^{2}$ University of Technology, Baghdad, Iraq. \\ ${ }^{3}$ Tyumen Industrial University, Volodarskogo str., 38, Tyumen, 625000, Russia
}

\begin{abstract}
This paper deals with using the stone column as a technique for the enhancement of the soft ground. The key goal of utilizing stone column is to decrease settlement and to increment the soil bearing ability, as well as decreasing the consolidation period. Nowadays, the current method concerns with various kinds of soil granular and cohesive. It is clear that the delicate soils (cohesive) possess a good settlement because of the disability of the ground to control the sidelong development and protruding of the stone sections. Moreover, the ways of utilization of the geosynthetic materials for encasement of the stone sections are other perfect ways to enhance the implementation, the quality, and firmness of stone segments. The present work investigates the behavior of the soft soil reinforced with ordinary and encased stone columns with geogrid under cyclic load. Six model tests were carried out on a soil with shear strength of about $15 \mathrm{kPa}$ for both ordinary stone columns (OSC) and geogrid encased stone columns (ESC). For validating the enhanced method of utilizing stone columns, finite element model using the software PLAXIS 3D and field load exams had been applied. It was concluded that the models subjected to cyclic loading under the rate of loading $10 \mathrm{~mm} / \mathrm{sec}$ reached the failure level faster than models tested under the rate of loading $5 \mathrm{~mm} / \mathrm{sec}$. The results of the finite element analyses of settlement compared with the records of settlement after the laboratory load tests seem to yield reasonably comparable values up to $50 \%$ of the design load. Afterwards, the recorded settlements show up to $60 \%$ higher values in compare with the results of the finite element analyses. This observation can be attributed to the occurrence of plastic failures under increasing load after an initial elastic response.
\end{abstract}

\section{Introduction}

There have been many strategies for enhancing the soil state, for example, lime heap, stone column stream grouting and compaction. Before utilizing any of these strategies, it's necessary to know the detail of the ground changes. It's a procedure that is utilized by a geotechnical specialist for solving the problems of feeble soil in-situ [1]. The soft clay soil has low quality and compressibility, and stone section containing a material compacted in

*Corresponding author: kwasally93@gmail.com 
the chamber is utilized as a system for enhancing the quality of fragile soil [2]. Greenwood and Krisch (1983) found that the presence of the stone columns creates a composite material of higher shear strength than in-situ soil and lower overall compressibility. When an axial load is applied at the top of a single stone column, the stiffness of the stone columns is provided by the lateral stress within the poor soil [3]. In the recent history, it is sated that the use of stone column became a traditional method. In addition, the stone column was limited to a diameter of $0.2 \mathrm{~m}$ and a length of $2 \mathrm{~m}$, and then this technology was developed with an increase in the reduction of stone columns with a diameter of $0.5-1.5 \mathrm{~m}$ and a length of $15 \mathrm{~m}$ [4]. Experimental studies were carried out by Kwa et al. (2018) to investigate the behavior of the stone column encased with Geogrid. Tests were carried out on a single installed stone column (ordinary and encased) in order to evaluate the effectiveness of the single column on bearing capacity and settlement. It was found that encasing the stone column with geogrid results in an increase in load carrying capacity and reduction in a settlement in comparison with the case without geogrid. By using geogrid, the ultimate bearing capacity increased by $60 \%$ compared to case without geogrid, and load-bearing capacity increased by $20 \%$ for 10 $\mathrm{mm}$ settlement. Numerical analysis will be carried out by using PLAXIS 3D to validate the test and to make comparison between them [5]. The present work studies the behavior of the soft soil reinforced with ordinary and encased stone columns with geogrid under cyclic load. Six model tests were carried out on a soil with undrained shear strength of about $15 \mathrm{kPa}$ for both tests of ordinary stone columns (OSC) and geogrid encased stone columns (ESC). For validating the enhanced method of utilizing stone columns, finite element model using PLAXIS 3D software and field load exams were used.

\section{Experimental Investigation}

\subsection{Materials}

\subsubsection{Clay soil}

The engineering properties of the site soils are identified by a number of laboratory tests. A brown clay soil was brought in Iraq from Baghdad city. Standard tests were performed to determine the physical and chemical properties of the soil; details are given in Table 1. The soil consists of $28 \%$ silt, $4 \%$ sand, and $68 \%$ clay, as it shown in the grain size distribution (Figure (2-1)). Performed tests and utilized relevant standards are listed below.

According to the sieve analyses, more than $50 \%$ of the soil passed No. 200 sieve, and Atterberg limit tests show that the plasticity index is $10 \%$. Whereas, the range of the liquid limit is between $37 \%$ and $40 \%$ with an average of $38.5 \%$. According to the Unified Soil Classification System USCS, the soils are classified as the clays (CL) with low plasticity and high plasticity $(\mathrm{CH})$. The water content varied within a range between $13 \%$ and $31 \%$

Table 1. Physical and chemical properties of clayey soil.

\begin{tabular}{|l|c|}
\hline \multicolumn{1}{|c|}{ Index property } & Index value \\
\hline Natural water content \% & 31 \\
\hline Liquid limit \% (LL) & 37 \\
\hline Plastic limit \% (PL) & 27 \\
\hline Shrinkage limit \% (SL) & 20 \\
\hline Plasticity index \%(PI) & 10 \\
\hline Activity $\left(\mathrm{A}_{\mathrm{t}}\right)$ & 0.60 \\
\hline Specific gravity (Gs) & 2.69 \\
\hline
\end{tabular}




\begin{tabular}{|l|c|}
\hline Gravel (larger than $4.75 \mathrm{~mm}) \%$ & 0 \\
\hline Sand $(0.074$ to $4.75 \mathrm{~mm}) \%$ & 4 \\
\hline Silt $(0.005$ to $0.074 \mathrm{~mm}) \%$ & 28 \\
\hline Clay $(<0.005 \mathrm{~mm})$ & 68 \\
\hline
\end{tabular}

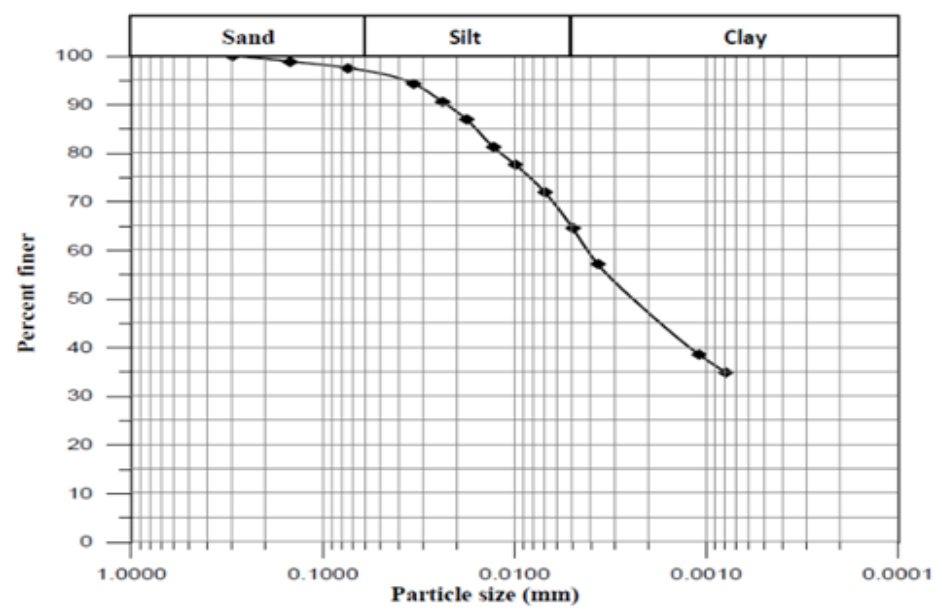

Fig. 0 Grain size distribution.

\subsubsection{Crushed stone}

The crushed stone materials were collected from a private mosaic factory. It was created as a result of crushing the big stones. The crushed stone has a white color and angular shapes. The estimate of the mechanical properties of stones, the internal friction angle of the construction, and the relative density of columns are estimated from past studies. The properties of the stone column are listed in Table 3. The aggregate used for the stone column element consists of poorly graded gravel.

Table 2. Properties of the stone column.

\begin{tabular}{|l|c|}
\hline \multicolumn{1}{|c|}{ Index } & value \\
\hline$(\gamma \mathrm{d}) \mathrm{max}$, Max. dry unit weight $\left(\mathrm{kN} / \mathrm{m}^{3}\right)$ & 17 \\
\hline$(\gamma \mathrm{d}) \mathrm{min}$, Min. dry unit weight $\left(\mathrm{kN} / \mathrm{m}^{3}\right)$ & 11.56 \\
\hline $\mathrm{D}_{10}(\mathrm{~mm})$ & 5.2 \\
\hline $\mathrm{D}_{30}(\mathrm{~mm})$ & 5.1 \\
\hline $\mathrm{D}_{60}(\mathrm{~mm})$ & 5.22 \\
\hline Specific gravity $(\mathrm{Gs})$ & 2.643 \\
\hline Coefficient of uniformity $(\mathrm{Cu})$ & 1.04 \\
\hline Coefficient of curvature $(\mathrm{Cc})$ & 0.956 \\
\hline
\end{tabular}

\subsubsection{Stone Column Installation}

The center of the rectangular box was properly marked and with a PVC pipe $(\mathrm{d}=70 \mathrm{~mm})$ placed in the center of the box. The clay was formed around this pipe. The layer was tamped with a metal tamper to remove the soil inside the pipe. The hand auger manufactured for this reason is used. The stone was charged carefully in the tube in 3 layers compacted by using $15 \mathrm{~mm}$ diameter rod in order to get the required unit weight of $17 \mathrm{kN} / \mathrm{m} 3$. The procedure of 
charging, compaction, and withdrawal of pipes was carried out together. Moreover, the preparatory layer was left for one day to obtain a uniform layer, which also ensured a suitable contact between the clay and the stone column. Ratio of length to diameter (L/D) is 8 , and area replacement ratio is 0.195 . Figure 2 illustrates the steps of preparation of stone column model.
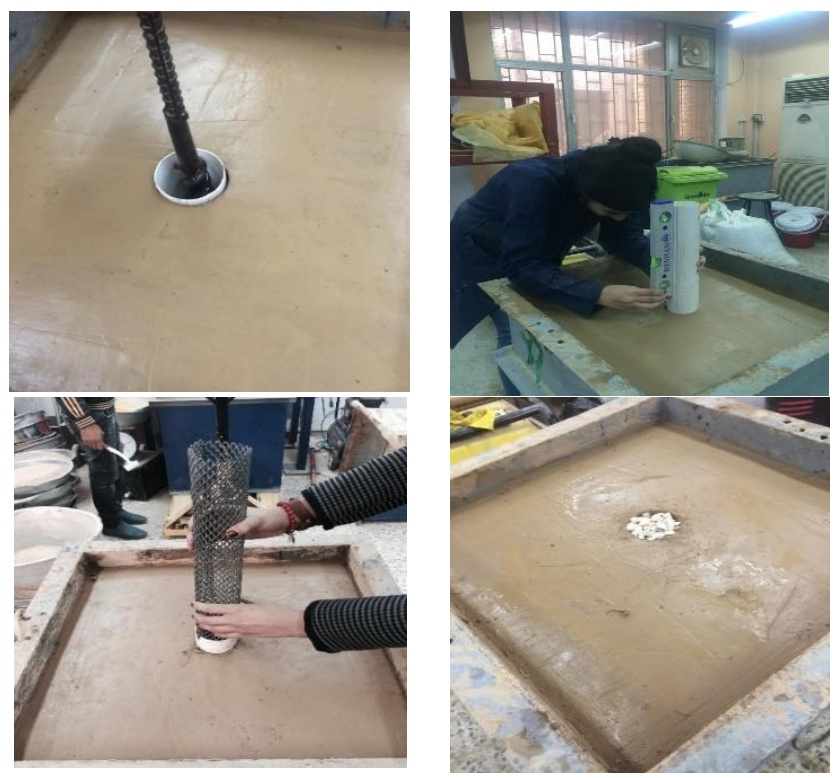

Fig. 2. Steps of stone column installation.

\subsection{Results and discussion}

As shown below in Figure 3, the model of untreated soil will fail faster than the model of soil reinforced with stone column. Otherwise, the model of the soil reinforced with ordinary stone column will fail at shorter time than the model of soil reinforced with stone column encased by geogrid material at the rate of $5 \mathrm{~mm} / \mathrm{sec}$. 


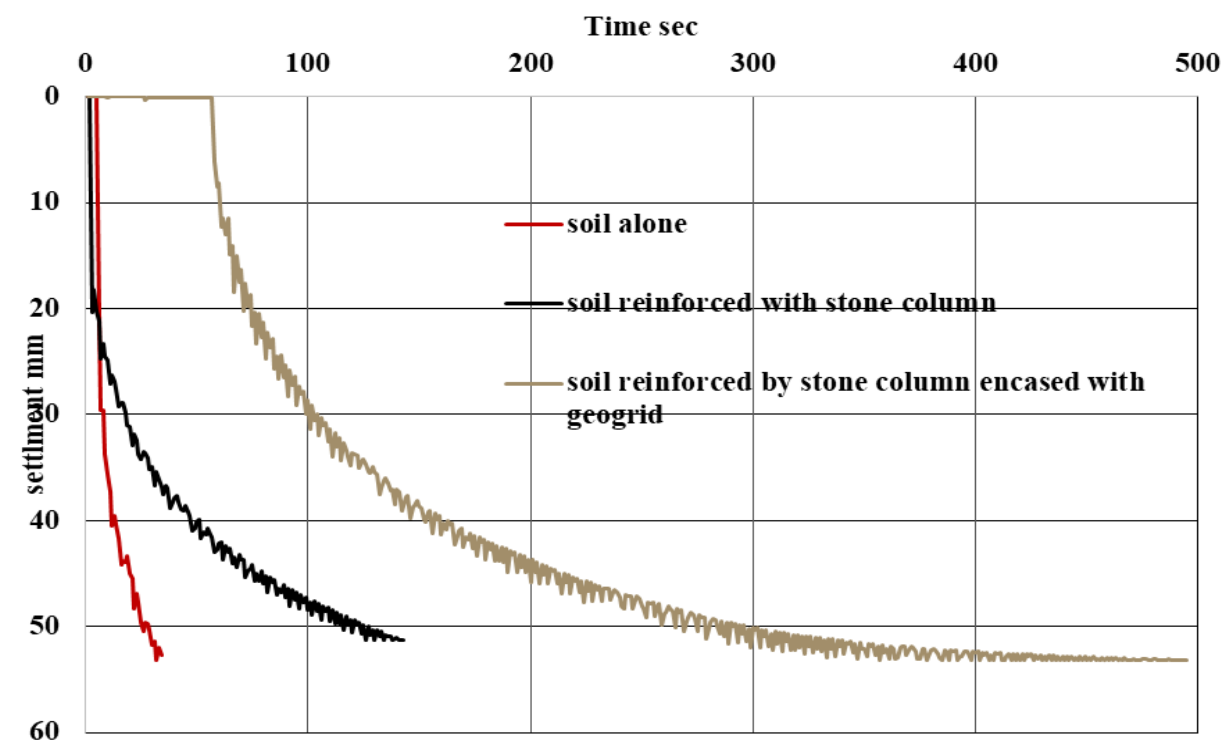

Fig. 3. Results of cyclic loading tests on untreated soil and soil reinforced with stone columns at the rate of $5 \mathrm{~mm} / \mathrm{sec}$.

Figure 4 presents the results of cyclic loading test for models tested under the rate of loading $10 \mathrm{~mm} / \mathrm{sec}$. The model of untreated soil will fail faster than the models of soil reinforced with stone column. Otherwise, the model of the soil reinforced with stone column will fail more than the model of soil reinforced with stone column encased by geogrid material. Also it can be described that the model at the rate of loading $10 \mathrm{~mm} / \mathrm{sec}$ will reach the failure faster and the value of the settlement will be more than the models at the rate of loading $5 \mathrm{~mm} / \mathrm{sec}$. The results are summarized in Table 3 .

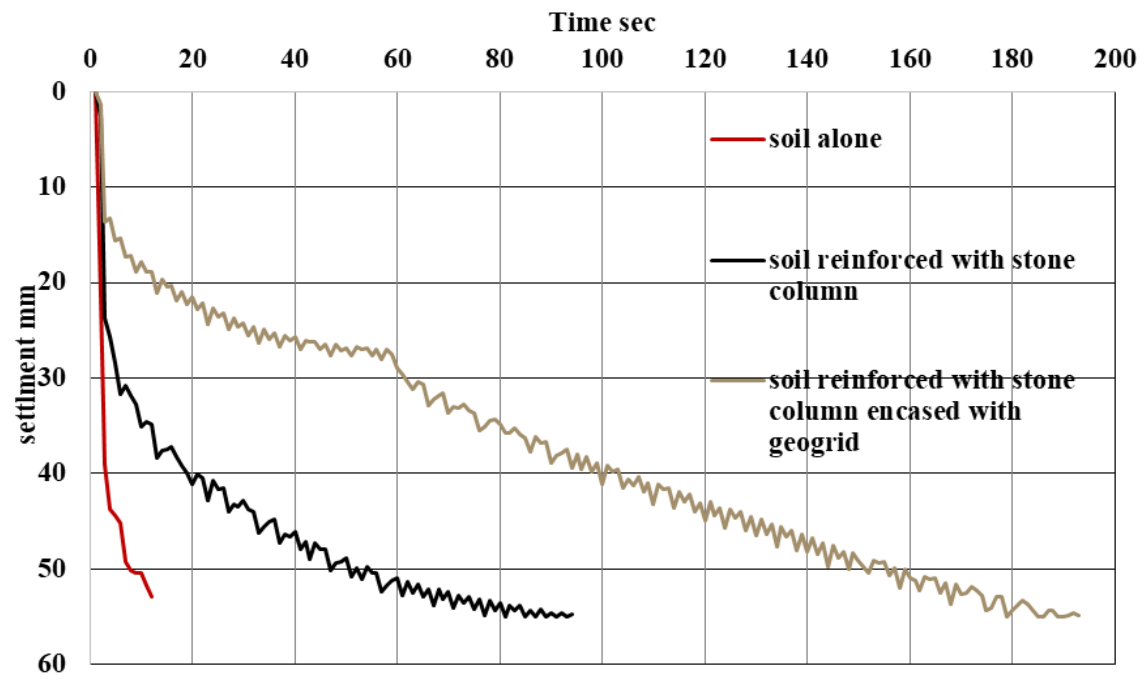

Fig. 4. Results of cyclic loading tests on untreated soil and soil reinforced with stone columns at the rate $10 \mathrm{~mm} / \mathrm{sec}$. 
Table 3. Summary of settlement of cyclic loading test on soft clay and clay reinforced with stone columns.

\begin{tabular}{|c|c|c|c|}
\hline $\begin{array}{c}\text { Rate of loading } \\
(\mathrm{Mm} / \mathrm{sec} .)\end{array}$ & $\begin{array}{c}\text { For untreated soil } \\
(\mathrm{mm})\end{array}$ & $\begin{array}{c}\text { Soil reinforced with ordinary } \\
\text { stone column } \\
(\mathrm{mm})\end{array}$ & $\begin{array}{c}\text { Soil reinforced with stone } \\
\text { column encased by geogrid } \\
(\mathrm{mm})\end{array}$ \\
\hline \multirow{2}{*}{5} & 30 & 12 & 2 \\
\cline { 2 - 4 } & 40 & 17 & 1 \\
\hline \multirow{2}{*}{10} & 40 & 22 & 13 \\
\cline { 2 - 4 } & 45 & 25 & 14 \\
\hline
\end{tabular}

\section{Finite element analysis}

Prediction of the load test results by the finite element analysis were compared with the model test results in term of time and settlement. The finite element analysis is done using PLAXIS 3D foundation V1 program.

\subsection{Material properties}

Materials of the soil and stone column are represented by the linear elastic-perfectly plastic Mohr-Coulomb model. The model requires five input parameters: Young's modulus (E) as the basic stiffness parameter, Poisson's ratio (v), internal friction angle ( $\square$ ), cohesion (c), and dilatancy angle $(\psi)$. Since groundwater is observed at the site and soils are fully saturated, an undrained analysis is chosen. Table 4 shows the material parameters utilized for soil and the stone columns.

\subsection{Boundary conditions}

In the finite element method, the same model as for the column plate load test in the field is created. The depth and width of the model are selected as sufficient, so that it acquires real behavior of the model. Standard boundary option is selected in the program. When considering the model boundary in yz-plane, displacements in the $\mathrm{x}$ directions are limited to zero, where displacements in the $y$ and $z$ directions are free. All boundaries are modeled in the same manner. The bottom boundary is fixed in all directions. It is important that a suitable mesh size is selected to be fine enough to capture the real behavior of the model. Due to that reason, the mesh size is selected in the medium range. The created geometry of the model and the generated mesh used in analyses are presented in Figure 5. The cyclic parameters are selected; the boundary conditions for the dynamic load are non-viscous in all directions, except the surface which is viscose.

Table 4. Parameters of the soil, column \& geogrid in PLAXIS 3D.

\begin{tabular}{|l|c|c|}
\hline Properties & Soft clay & Stone column \\
\hline Unsaturated unit weight,$\gamma_{\text {unsat }}\left(\mathrm{kN} / \mathrm{m}^{3}\right)$ & 13.8 & 15 \\
\hline Saturated unit weight, $\gamma_{\text {sat }}\left(\mathrm{kN} / \mathrm{m}^{3}\right)$ & 18.3 & 16.6 \\
\hline Material model & Hardening soil & Mohr-coulomb \\
\hline Drainage type & Undrained $(\mathrm{B})$ & Draind \\
\hline $\mathrm{E}(\mathrm{kPa})$ & 10300 & 95000 \\
\hline Power $(\mathrm{m})$ & 1 & - \\
\hline Cohesion, $\mathrm{Cu}(\mathrm{kPa})$ & 15 & 1 \\
\hline Friction angle, $\square \mathrm{u}(\mathrm{deg})$ & - & 40 \\
\hline Geogrid stiffness, $\mathrm{J}(\mathrm{kN} / \mathrm{m})$ & - & 68 \\
\hline
\end{tabular}




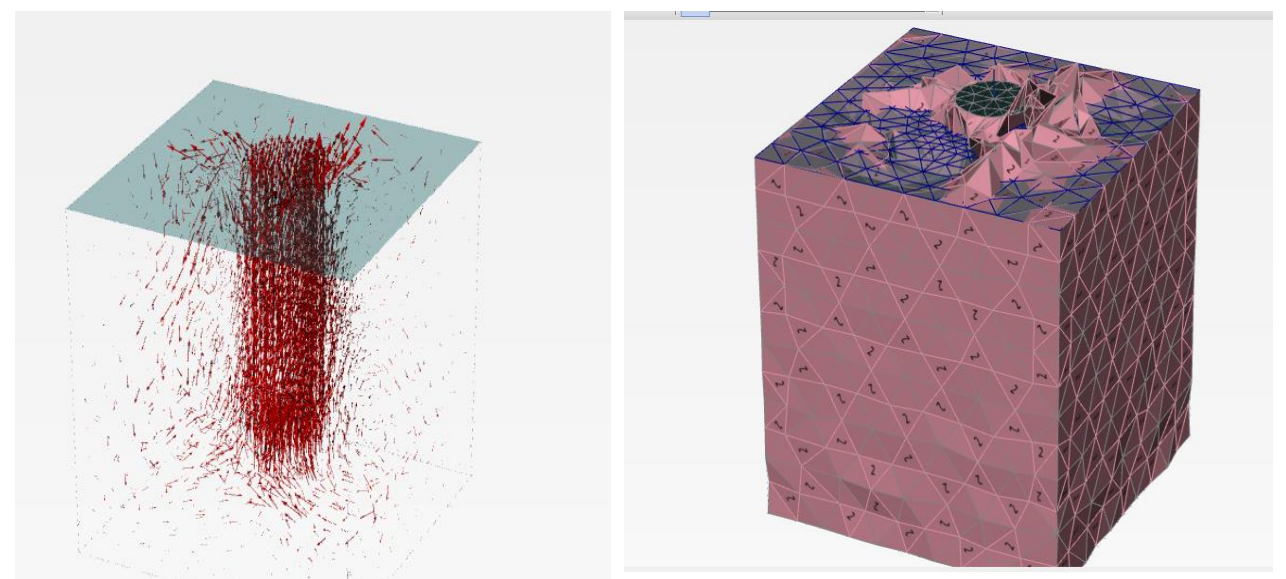

Fig. 5. Input geometry of the analyzed model for soil encased with stone column in PLAXIS 3D.

\subsection{Results and discussion}

Since it is necessary to compare the results for numerical analysis, Figure 6 shows the final comparison of three models in PLAXIS 3D. From Figure 6, it can be noted that the settlement decrease for soil reinforced by stone column in compare with untreated soil. Moreover, for the soil reinforced by stone column encased with geogrid material, settlement is less than for the soil reinforced with ordinary stone column.

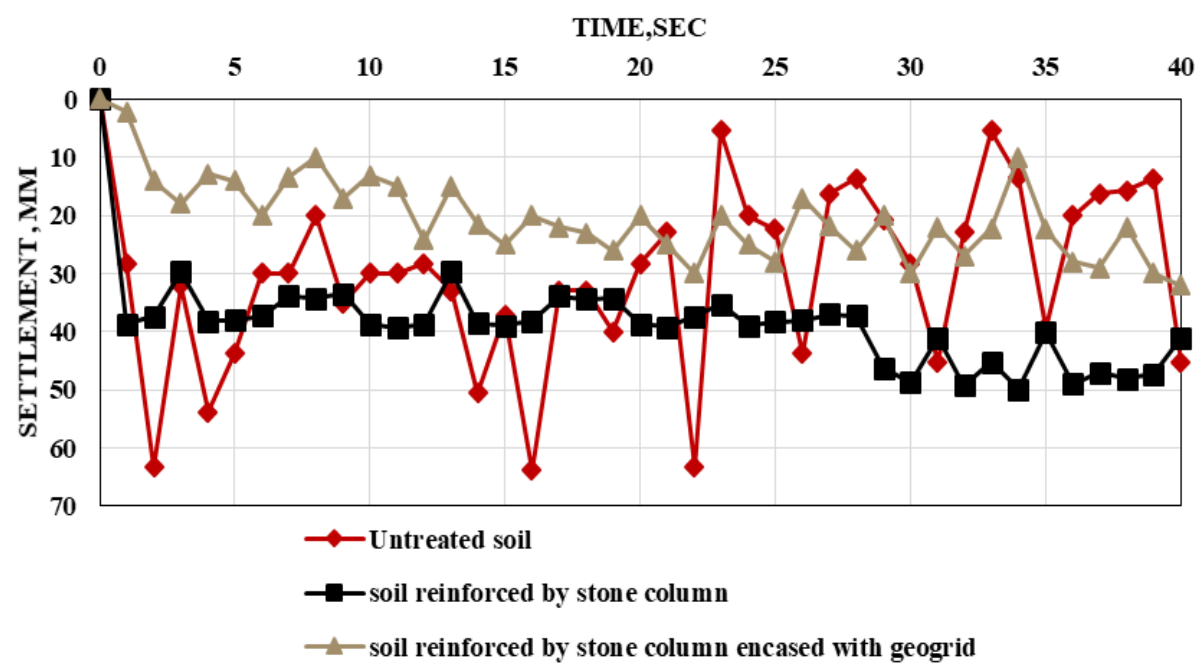

Fig. 6. Results of finite element analysis of soil reinforced by stone column under cyclic loading.

\section{Validation of the Models}

Figure 7 shows the dependence of settlement on time for improved and unimproved soil based on model tests and finite element analysis for single column. Figure 8 shows the dependence of settlement on time for a single column reinforced clay soil based on the model tests and finite element analysis. Figure 9 indicates the dependence of settlement on time for a single stone column encased by geogrid based on the model tests and finite element 
analysis. Figure 10 shows that the difference between the PLAXIS work and the laboratory work for untreated soil is small. Both of them gave a high value of settlement at 19 th sec, 40 $\mathrm{mm}$ and $47 \mathrm{~mm}$, respectively.

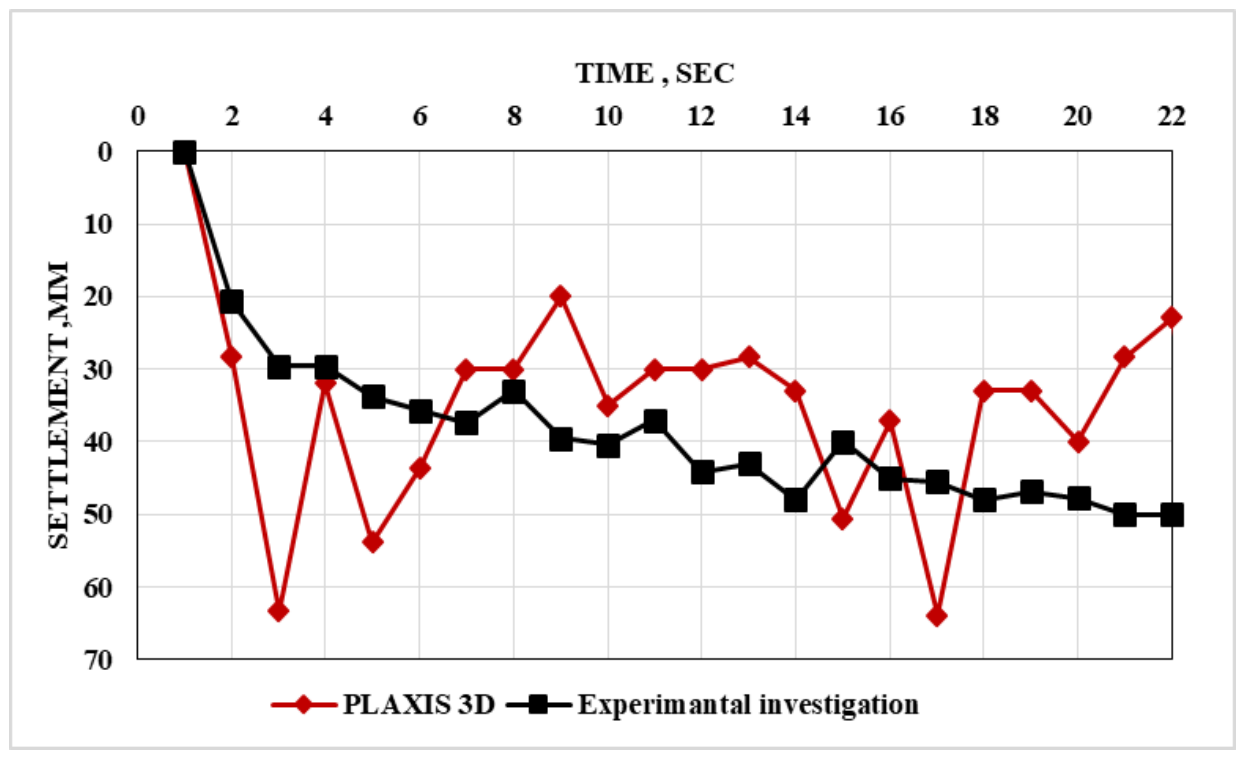

Fig. 7. Validation by numerical analysis of the model for untreated soil.

Figure 8 shows the difference between the PLAXIS results and the laboratory work for soil reinforced by ordinary stone column. It can be noted that both of them gave a value of settlement at 135 th sec, $50 \mathrm{~mm}$, and $51 \mathrm{~mm}$, respectively.

From these values, it can be noted that the stone column reduces the value of settlement in both models and can be used as a method for soil improvement.

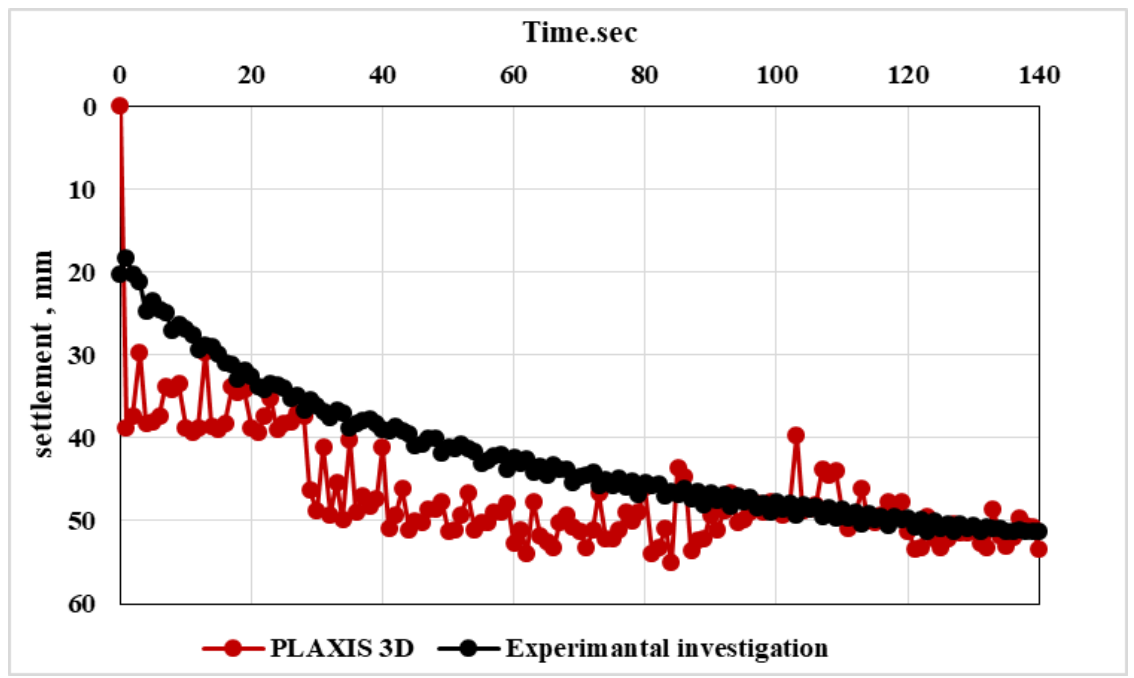

Fig. 8. Validation by numerical analysis of the model for soil reinforced with stone column.

Figure 9 shows the difference between the PLAXIS results and the laboratory work for soil reinforced by ordinary stone column encased with a geogrids material. It can be noted that both of them gave a value of settlement at $100 \mathrm{sec}, 40 \mathrm{~mm}$ and $30 \mathrm{~mm}$, respectively. 
From these values, it can be noted that the geogrid material reduces the value of settlement in both models.

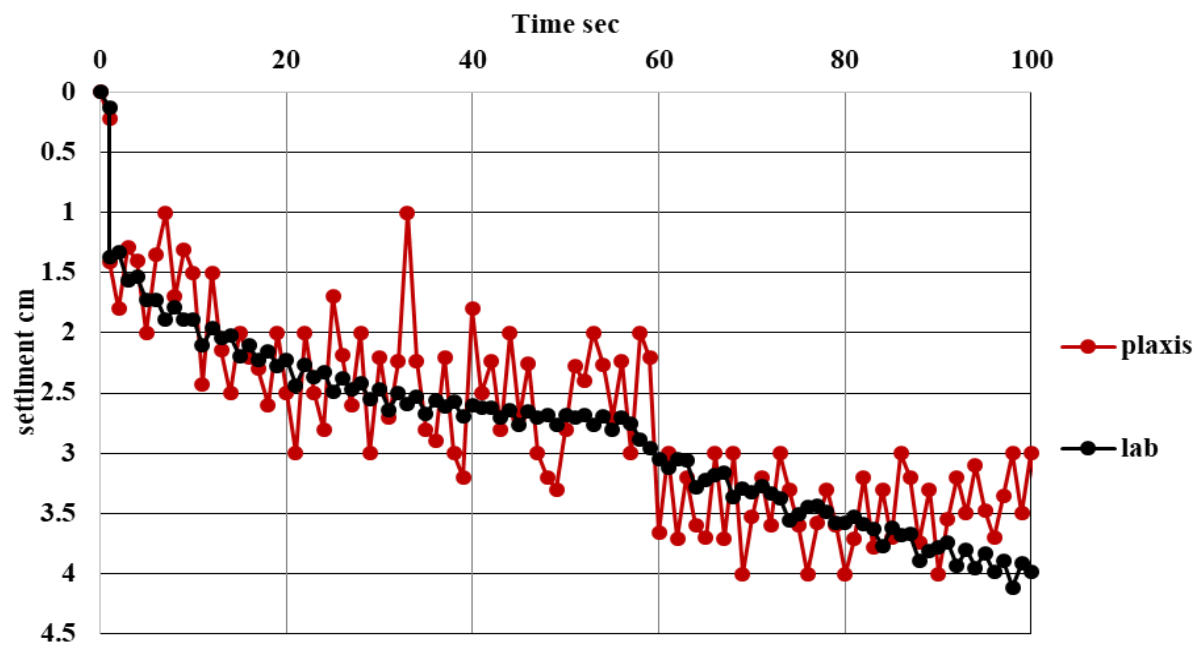

Fig. 9. Validation by numerical analysis of the model for soil reinforced with stone column encased with geogrid.

The previous figures indicate good convergence between the numerical and experimental results. The comparison is summarized in Figure 10.

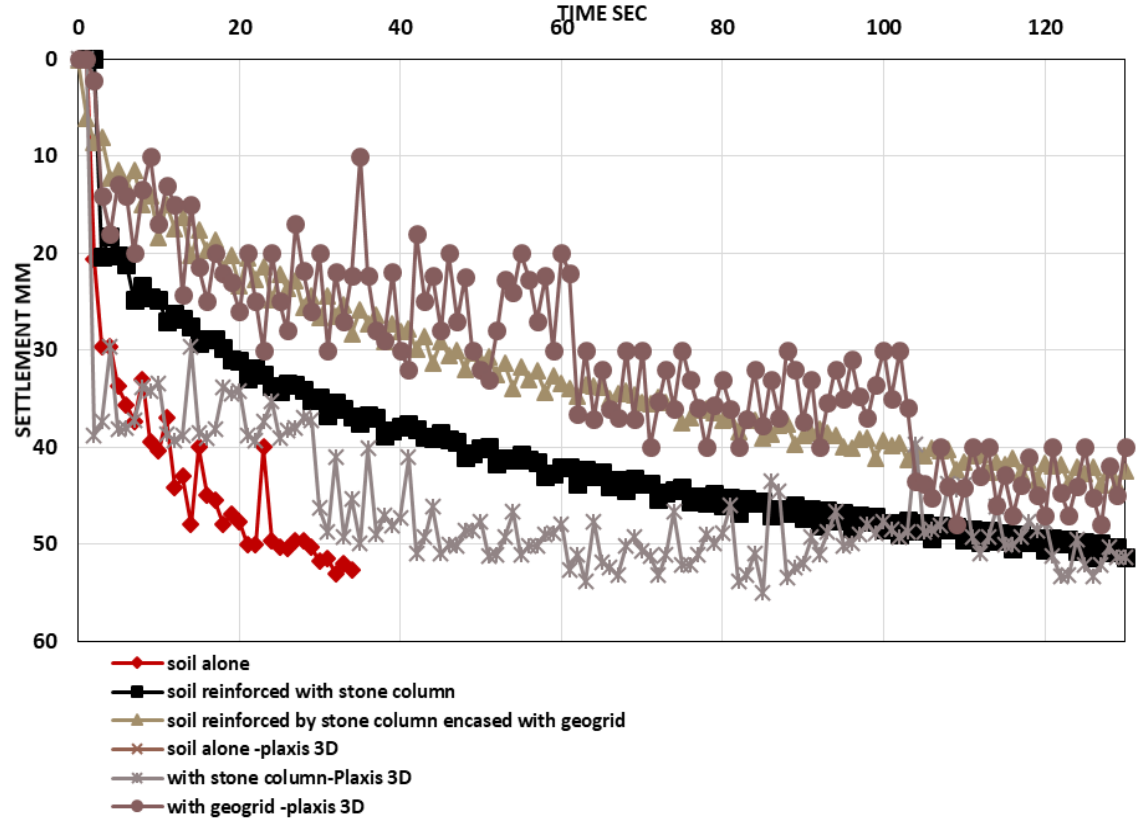

Fig. 10. Comparison of models under cyclic load for PLAXIS 3D and experimental investigation.

\section{Conclusions}

1. For the models of soft soil reinforced by stone column subjected to cyclic load below the threshold loading rate $5 \mathrm{~mm} / \mathrm{sec}$, reinforced soils were less sensitive to the number of 
loading application than ordinary soil (no column). This is due to the compaction of column materials that occurs during loading, which leads to an increase in density and results in greater resistance to deformation and, consequently, to a lower settlement.

2. The models subjected to cyclic loading at the rate of loading $10 \mathrm{~mm} / \mathrm{sec}$ reached the failure level faster than models tested at the rate of loading $5 \mathrm{~mm} / \mathrm{sec}$.

3. The results of numerical analysis coincide with experimental studies. From the results of the calculations shown in the figures, it can be said that with the design stress, the calculated settlements and the results of the finite elements analysis are in good agreement with each other. However, with the increase of applied stress, especially when it exceeds the allowable bearing capacity, the plastic failures seem to become noticeable. This can be observed from the differences between calculated and recorded settlements.

4. Settlement based on the finite element analyses compared to settlement recorded during the laboratory load tests give fairly comparable values up to $50 \%$ of the design load. Besides, the recorded settlements show up to $60 \%$ higher values compared to the results of the finite element analyses. This observation can be attributed to the occurrence of plastic failures under increasing demand after the initial elastic response.

\section{References}

1. D.T. Bergado, L.R. Anderson, N. Miura, A.S. Balasubramaniam, ASCE press 4, 427 (1994)

2. S. Dipty, M. Girish, Suitability of different material for stone column construction, Elctronic journal of Geotechnical engineering (2009)

3. D.A. Greenwood, K. Krisch, Specialist ground treated by vibratory and dynamic methods, Proceedings of Advances in Piling and Ground Treatment for Foundation, Institution of Civil Engineers (1983)

4. Z. Guetif, M. Bouasside, J. Debats, Computers and Geotechnics 34(2), 104-111 (2007)

5. S.F. Kwa, E.S. Kolosov, M.Y. Fattah, Construction of Unique Buildings and Structures 66(3), 49-59 (2018) 